\title{
Anticoagulant activity in salivary gland homogenates of Thyrsopelma guianense (Diptera: Simuliidae), the primary vector of onchocerciasis in the Brazilian Amazon
}

\author{
Andrezza Campos Chagas ${ }^{1 /+}$, Jansen Fernandes Medeiros ${ }^{2}$, Spartaco Astolfi-Filho ${ }^{3}$, Victor Py-Daniel ${ }^{4}$ \\ ${ }^{1}$ Laboratório de Entomologia Médica, Instituto de Pesquisa René Rachou-Fiocruz, Belo Horizonte, MG, Brasil ²Coordenação de Pesquisas \\ em Ciências da Saúde ${ }^{4}$ Núcleo de Ciências Humanas e Sociais, Instituto Nacional de Pesquisas da Amazônia, Manaus, AM, Brasil \\ ${ }^{3}$ Laboratório de Tecnologias de DNA, Centro de Apoio Multidisciplinar, Universidade Federal do Amazonas, Manaus, AM, Brasil
}

In this study, anticoagulant activity was detected in salivary gland homogenates (SGHs) of Thyrsopelma guianense (Diptera: Simuliidae). The SGH yielded $1.07 \mu \mathrm{g} \pm 0.03(n=15)$ of total soluble protein per pair of glands. In addition, following SDS-PAGE (12.5\% gel) and silver nitrate staining, 12 polypeptides with molecular weights ranging from 14-69 kDa were detected in all physiological ages analyzed (12 h, $24 \mathrm{~h}, 48 \mathrm{~h}$ and $72 \mathrm{~h}$ following emergence). Coagulation bioassays showed that the SGHs had activities that interacted at all levels of coagulation (the intrinsic, extrinsic and common pathways), by extending the plasma recalcification time, prothrombin time, thrombin time. This is the first report on the activity of salivary gland proteins from the main vector of onchocerciasis in Brazil. We also suggest detailed studies on the morphology and function of the salivary glands in order to understand the role of these proteins in host/vector interactions.

Key words: black flies - salivary glands - anticoagulant - onchocerciasis

Human onchocerciasis (river blindness) is caused by the nematode Onchocerca volvulus (Nematoda: Onchocercidae), which is transmitted through the bite of female black flies (Diptera: Simuliidae). This disease is endemic in 34 countries, 27 of which are in Africa, one is in the Arabian Peninsula and six are in Latin America. Recently, all six countries in the Americas with endemic onchocerciasis introduced programs providing treatment in all 13 foci and all six have exceeded the target coverage of treating $85 \%$ of the eligible population twice a year (Sauerbrey 2008).

In Brazil, black fly saliva was determined to be responsible for the wild fire disease (Pemphigus foliaceus, also known as bulbous autoimmune disease) (Auad 1972, Lombardi et al. 1992). It was also named as the cause of death in immigrants suffering from Altamira hemorrhagic syndrome (Pinheiro et al. 1974), characterized by hemorrhage of the skin around the bites (multiple petechiae and ecchymosis), bleeding mucosa and anemia.

The ability to hematophage evolved independently in different groups of arthropods (Ribeiro 1995). New compounds arose which allowed these organisms to avoid the hemostasis of the vertebrate host, making the saliva a rich source of antihemostatic molecules (Ribeiro \& Francischetti 2003, Champagne 2004, 2005). These include a great diversity of vasodilators (Lerner et al. 1991,

\footnotetext{
Financial support: FAPEAM, CNPq (Msc scholarship for ACC)

+Corresponding author: achagas@cpqrr.fiocruz.br

Received 8 August 2009

Accepted 10 November 2009
}

Law et al. 1992, Champagne \& Ribeiro 1994, Cupp et al. 1994, 1998), inhibitors of platelet aggregation (Cupp et al. 1993, 1995, Moreira-Ferro et al. 1999, Valenzuela et al. 2001) and inhibitors of blood coagulation (Jacobs et al. 1990, Abebe et al. 1995, 1996, Capello et al. 1996, Stark \& James 1998, Valenzuela et al. 1999, Cupp et al. 2000, Horn et al. 2000, Zang et al. 2002).

Past studies of black flies' salivary glands are limited to the species Simulium vittatum (= Psilozia vittata Zetterstedt) due to the absence of colonies. The first report described morphological aspects of the salivary glands for this species (Hungerford 1913, Cox 1938, Rubtzov 1955) and only recently have oriental black fly species been investigated (Jariyapan et al. 2006). The salivary glands have been suggested as a tool in the identification of different species of black flies (Bennett 1963).

Recently, the salivary glands of black flies have been investigated due to their important roles in blood feeding and in the transmission of filarial parasites to man (Cupp \& Cupp 1997). The female black flies exhibit pool feeding behaviour where their salivary proteins are injected at the injury site and maintain the blood meal in a fluid state due to the antihemostatic properties present in the saliva. These proteins include anticoagulants (Jacobs et al. 1990, Abebe et al. 1994, 1995, 1996), vasodilators (Cupp et al. 1994), modulators of platelet aggregation as mediated by apyrase (Cupp et al. 1993, 1995) and modulators of the mouse cellular immune response (Cross et al. 1993).

Andersen et al. (2009) uncovered for the first time the sialo-transcriptome of a member of the Simuliidae family and identified several new protein families with pharmacological or antimicrobial activities that might serve as epidemiological markers of Simulium exposure or as anti-disease vaccines (Cupp \& Cupp 1997). 
In this paper we describe the anticoagulant activity and the electrophoretic protein profile from Thyrsopelma guianense (= Simulium guianensis Wise) salivary glands. This represents the first data on the salivary glands of a black fly involved in the transmission of $O$. volvulus in Brazil.

\section{MATERIALS AND METHODS}

Black flies - Nulliparous females were collected as pupae attached to plant material from breeding sites near the 40 Ilhas waterfall $\left(0^{\circ} 28^{\prime} 48^{\prime \prime} \mathrm{N} / 60^{\circ} 29^{\prime} 49^{\prime \prime} \mathrm{O}\right)$ in Pitinga village, municipality of Presidente Figueiredo, state of Amazonas, Brazil. The collections were made in two months (March and September) of 2004. Black flies were maintained on a glucose solution (honey Karo $^{\circledR}$ ) and given water ad libidum to promote accumulation of salivary secretions. The salivary glands were dissected at $12 \mathrm{~h}, 24 \mathrm{~h}, 48 \mathrm{~h}$ and $72 \mathrm{~h}$ following emergence and processed immediately as described below.

Salivary gland dissection - The salivary glands of the adult black flies were dissected individually using fine entomological needles under a stereoscopic microscope in $0.15 \mathrm{M} \mathrm{NaCl} \mathrm{pH} \mathrm{7.4.} \mathrm{Each} \mathrm{pair} \mathrm{of} \mathrm{glands} \mathrm{was} \mathrm{stored} \mathrm{in}$ a microcentrifuge tube with a small volume of $\mathrm{NaCl}$ at $-80^{\circ} \mathrm{C}$, pending later analysis.

Salivary gland homogenates ( $S G H s$ ) - Salivary glands were centrifuged at $10.000 \mathrm{~g}, 4^{\circ} \mathrm{C}$ for $10 \mathrm{~min}$ after which supernatants were removed. Supernatants were pooled and referred to as SGHs. Serial dilutions of SGHs were tested in coagulation assays.

Protein quantification - The soluble proteins were quantified according to Bradford (1976), using the dye Coomassie Brilliant Blue G-250. The protein concentration was determined based on a bovine serum albumin standard curve.

SDS-PAGE and silver staining - SDS-PAGE was carried out on a $12.5 \%$ gel according to Laemmli (1970) and the proteins were stained with silver nitrate. Low molecular weight protein markers (Amersham Biosciences) were used. The electrophoretic profiles were determined with a pool of three SGHs at different physiological ages (12 h, $24 \mathrm{~h}, 48 \mathrm{~h}$ and $72 \mathrm{~h}$ after emergence).

Coagulation assays - The assays were conducted as described by Valenzuela et al. (1996) with some modifications. Human citrated plasma as well as all the kits used to measure thrombin time (TT - thrombin activity assay) and prothrombin time (PT - extrinsic pathway assay) were provided by HUMAN GmbH (Germany) and were used to determine the anticoagulant activities of black fly SGHs. All assays were undertaken using the SGH of a newly emerged female (12 $\mathrm{h}$ after emergence).

Recalcification time (RT) - A Biotrak II Plate Reader (Amersham Biosciences) with a kinetic module was used to measure clotting activity by the RT procedure. Briefly, citrated human plasma $(20 \mu \mathrm{L})$ was incubated with $20 \mu \mathrm{L}$ of $150 \mathrm{mM} \mathrm{NaCl}, \mathrm{pH} 7.4$, either with or without the sample to be tested (SGH). Samples were mixed in the wells of a 96-well flat-bottom plate and then incubated at $37^{\circ} \mathrm{C}$ for $5 \mathrm{~min}$. The coagulation cascade was triggered by addition of $20 \mu \mathrm{L}$ of pre-warmed $20 \mathrm{mM} \mathrm{CaCl}_{2}$. The plate was placed in the microplate reader, mixed and heated at $37^{\circ} \mathrm{C}$ to take absorbance readings at $620 \mathrm{~nm}$ every $10 \mathrm{sec}$. Data were recorded using the "time to selected absorbance" option in the microplate reader's Softmax software. All assays on fibrin clot formation were performed with eight replications of all dilutions.

The other assays were carried out in the same way except for the substitution of $20 \mu \mathrm{L}$ of prewarmed Thromboplastin SI reagent (lyophilized thromboplastin from rabbit brain with the addition of calcium chloride); or $20 \mu \mathrm{L}$ of RGT reagent (lyophilized bovine thrombin, $10 \mathrm{NIH} \mathrm{U} / \mathrm{mL}$ ) for the PT and TT assays, respectively. After $3 \mathrm{~min}$ of incubation at $37^{\circ} \mathrm{C}, 20 \mu \mathrm{L}$ of pre-warmed $20 \mathrm{mM} \mathrm{CaCl}_{2}$ was added to each sample to initiate the reaction in the plate reader as cited above.

Statistical analysis - The results were expressed as mean \pm SEM. For statistical analysis, a one-way ANOVA and a Tukey test were used. Values were considered to differ significantly at $\mathrm{p}<0.001$.

\section{RESULTS}

Female SGHs contained $1.07 \mu \mathrm{g} \pm 0.03(\mathrm{n}=15)$ of total soluble protein per pair of glands (isolated from a single fly). The protein profiles of female salivary glands up until the third day following adult emergence are shown in Fig. 1. The protein profile did not change with age proteins present on the first day were present throughout the stages tested.

The analysis of the female salivary gland proteins by SDS-PAGE revealed the presence of 10-12 main polypeptides. The majority of the bands are between 14-69 $\mathrm{kDa}$ in mass. This profile (Fig. 1) showed nine bands $(69,64,41,39,33,31,28,16,15 \mathrm{kDa})$, all of which are abundant and present up to $72 \mathrm{~h}$.

The salivary glands of $T$. guianense show anticoagulant activity increasing RT (Fig. 2). The activity of the intrinsic, extrinsic and common pathways was determined using recalcification, PT and TT assays, respectively (Figs 2-4).

The time of normal human plasma clotting was higher than one hour (the latest time point observed) when tested using homogenates from five pairs of salivary glands. In addition, clotting time was significantly delayed ( $p<0.001)$ by as little as 0.312 of SGH in the recalcification assay (Fig. 2) indicating an inhibitory effect on the intrinsic pathway.

The inhibition of the extrinsic pathway was measured using the PT assay (Fig. 3) and it showed a statistically significant difference at $0.625 \mathrm{SGH}$ as that used on the previous assay. The inhibition of the common pathway was measured using the TT assay (Fig. 4) where 1.25 $\mathrm{SGH}$ was required to produce inhibition with equally significant statistical difference $(\mathrm{p}<0.001)$.

\section{DISCUSSION}

In this work, we report for the first time the presence of anticoagulant activity in SGH of the main vector of 


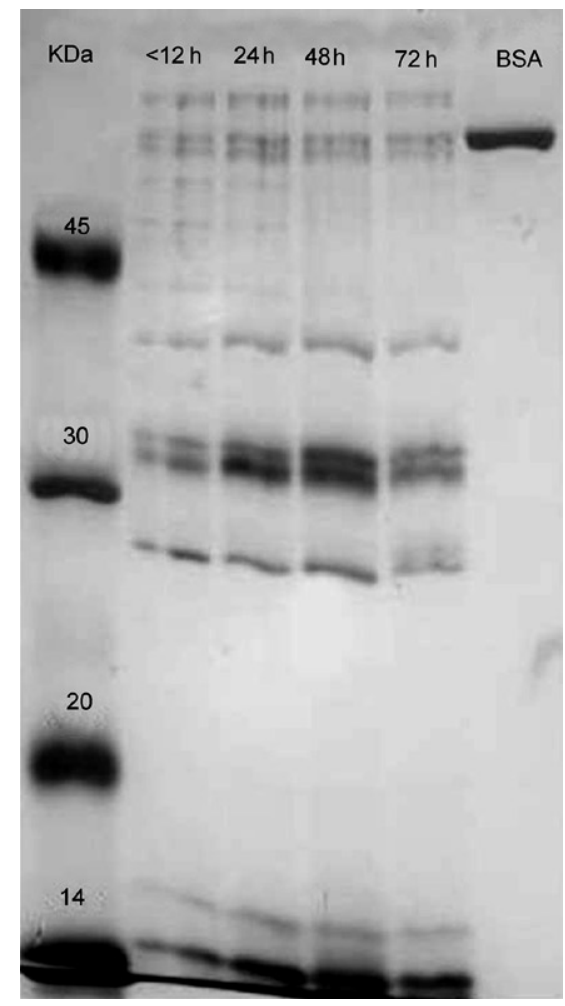

Fig. 1: protein electrophoretic profile of salivary glands Thyrsopelma guianense dissected at different times after adult emergence was separated by SDS-PAGE in a $12.5 \%$ polyacrylamide gel and silver stained. Relative molecular weights are indicated on the left side of the picture (low molecular weight, Amersham Biosciences). The number in the top picture indicated the hours after emergence. The number of salivary glands applied was $n=5(12 \mathrm{~h}, 24 \mathrm{~h}$ and $48 \mathrm{~h})$ and $\mathrm{n}=3$ for $72 \mathrm{~h}$ after emergence.

onchocerciasis in Brazil. As a preliminary study, only salivary glands of newly emerged females were studied, due to the lack of biological knowledge on this species and the subsequent difficulty of obtaining and maintaining this species under laboratory conditions. Recently, due to increased interest in the salivary glands of this species, efforts have been made to rear this fly.

Several salivary glands of hematophagous invertebrates have been intensively studied because they possess a variety of substances that are involved in counteracting the homeostatic systems and inflammatory reactions of the vertebrate host (Ribeiro 1987, 1995, Andrade et al. 2005). In black flies, the study of salivary secretion function has been limited to the species $S$. vittatum (Jacobs et al. 1990, Cross et al. 1993, Cupp et al. 1993, 1994, Abebe et al. 1994, 1995, 1996, Andersen et al. 2009).

$T$. guianense is the Neotropical vector species responsible for onchocerciasis transmission in the Yanomami area (Brazil). We show that the salivary glands of this species begin synthesizing proteins soon after adult emergence, similar to the protein expression observed in mosquitoes. The levels of soluble proteins present in

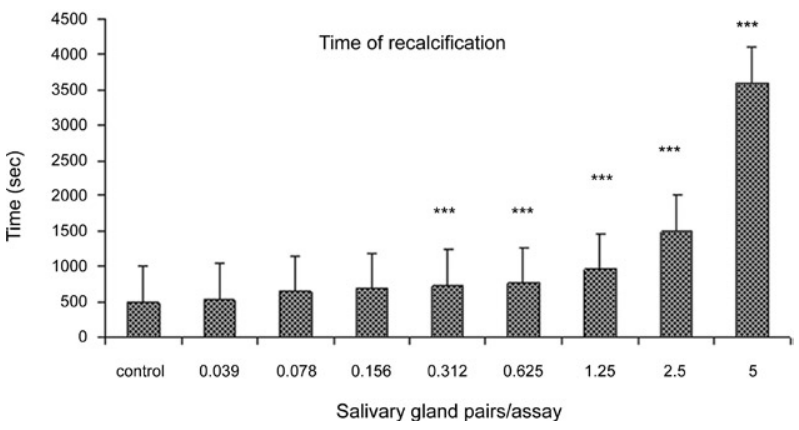

Fig. 2: anticlotting activity by Thyrsopelma guianense salivary glands homogenates. The recalcification time of commercial human platelet poor plasma was measured in the absence (control) or presence of salivary glands homogenates (SGH) containing the indicated number of gland pairs (SGH). Asterisks indicate the differences in recalcification time between the control and treatments: 5, 2.5, 1.25, 0.625, 0.312 SGH. Asterisks mean: $\mathrm{p}<0.001$.

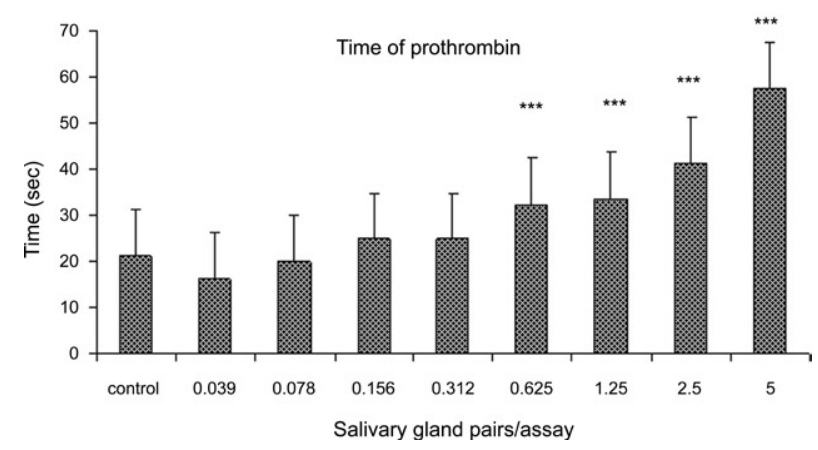

Fig. 3: anticlotting activity by Thyrsopelma guianense salivary glands homogenates $(\mathrm{SGH})$. The prothrombin time (PT) of commercial human platelet poor plasma was measured in the absence (control) or presence of SGH containing the indicated number of SGH. Asterisks indicate the differences in PT between the control and treatments: 5, 2.5, 1.25, 0.625, EGS. Asterisks mean: $\mathrm{p}<0.001$.

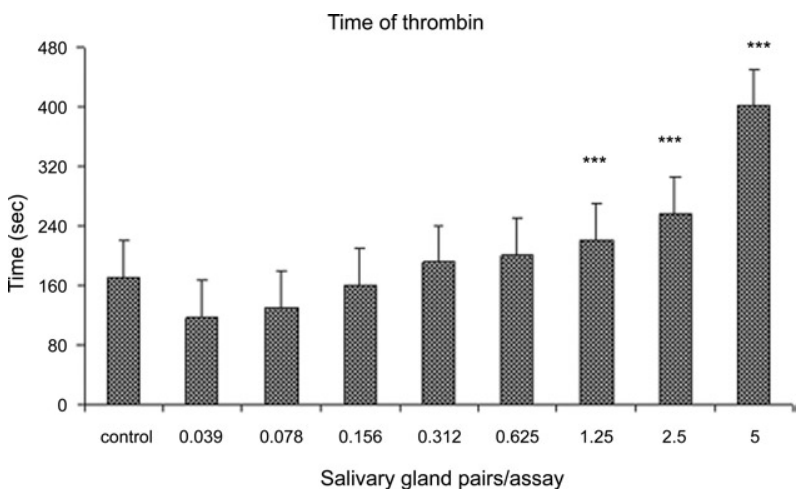

Fig 4: anticlotting activity by Thyrsopelma guianense salivary glands homogenates (SGH). The thrombin time (TT) of commercial human platelet poor plasma was measured in the absence (control) or presence SGH containing the indicated number of gland pairs (SGH). Asterisks indicate significant differences in TT between the control and treatments: 5, 2.5, 1.25, 0.625 SGH. Asterisks mean: $\mathrm{p}<0.001$. 
the salivary secretions are comparable to other anthropophilic species already studied, such as Simulium metallicum and S. ochraceum (Cross et al. 1993, Abebe et al. 1994). The protein level reflects the size of the salivary glands of each species, according to Jariyapan et al. (2006), who studied salivary protein levels in four oriental black fly species.

The electrophoretic profile of $T$. guianense is shown to be more similar to other black fly species already studied with regard to the number of polypeptides (1012 bands) and the fact that their expression changes with salivary gland maturation. Cross et al. (1993) analyzed four black flies species and found that zoophilic species had more bands (19-20 molecular bands) than anthropophilic species (11-12 molecular bands). This observation suggested that the difference in salivary protein composition may represent different evolutionary adaptations in anthropophilic species to aid feeding from human hosts.

In addition, the differences in protein level at different developmental stages, as visualized by SDS-PAGE, reflect an increase in the amount of protein in the glands of older black flies. This observation may be associated with the fact that efficient blood feeding occurs mainly during the time of peak maximum salivary secretions - at $48 \mathrm{~h}$ following emergence for this black fly species (Chagas, unpublished observations).

In sand flies, which are pool feeders like black flies, the number of protein components gradually increases with age and depends not only on sex but also on the physiological state in the female (Volf et al. 2000). In contrast, our results showed that the protein concentration of the black fly salivary glands did not vary qualitatively during the first three days of female adult life. Jariyapan et al. (2006) show that all black fly species studied had a small number of major proteins and that some of the major proteins differed in molecular mass between species.

Our results show that the proteins responsible for inhibiting the coagulation cascade are secreted soon after emergence. It is possible that the anti-coagulation activity may be even greater than that shown here if the flies are measured at the peak of salivation.

It was not possible to investigate the targets of the inhibitory saliva proteins. In this study, we show that the PT was prolonged with less efficiency than the RT, but our results suggest that both pathways are affected. We believed that this may be due to factors localized in common pathways, as factors Xa and thrombin from T. guianense $\mathrm{SGH}$ are able to inhibit all pathways (extrinsic, intrinsic and common).

The antihemostatic molecules present in salivary glands reflect the blood meal strategy used by each species. The data for black flies shows that the different strategies are associated with the meal mode (zoophilic or anthropophilic) and that these key components reflect the vector competence of the black fly species (Cupp \& Cupp 1997).

In the Yanomani area, four species were found to be responsible for the transmission of $O$. volvulus (PyDaniel 1997), however is not yet known what factors are making $T$. guianense the main vector in this area. Therefore, more investigations need to be undertaken into the antihemostatic molecules present in the salivary glands of this species in order to determine the vector competence.

\section{ACKNOWLDEGMENTS}

To Dr. Mary Cupp, for critical review manuscript.

\section{REFERENCES}

Abebe M, Cupp MS, Champagne D, Cupp EW 1995. Simulidin: a black fly (Simulium vittatum) salivary gland protein with antithrombin activity. J Insect Physiol 41: 1002-1006.

Abebe M, Cupp MS, Ramberg FB, Cupp EW 1994. Anticoagulant activity in salivary gland extracts of black flies (Diptera: Simuliidae). J Med Entomol 31: 908-911.

Abebe M, Ribeiro JMC, Cupp MS, Cupp EW 1996. Novel anticoagulant from salivary glands of Simulium vittatum (Diptera: Simuliidae) inhibits activity of coagulation factor V. J Med Entomol 33: $173-176$.

Andersen JF, Pham VM, Meng Z, Champagne DE, Ribeiro JMC 2009. Insight into the sialome of the black fly, Simulium vittatum. J Proteome Research 8: 1474-1488.

Andrade BB, Teixeira CR, Barral A, Barral-Netto M 2005. Haematophagous arthropod saliva and host defense system: a tale of tear and blood. An Acad Bras Cienc 77: 665-693.

Auad A 1972. Pênfigo foliáceo Sul Americano no estado de Goiás. Rev Patol Trop 1: 293-346.

Bennett GF 1963. The salivary gland as an aid in the identification of some Simuliids. Can J Zool 41: 948-952.

Bradford MM 1976. A rapid and sensitive method for the quantitation of microgram quantities of protein utilizing the principle of protein-dye binding. Anal Biochem 72: 248-254.

Cappello M, Bergum PW, Vlasuk GP, Furmidge BA, Pritchard DI, Aksoy S 1996. Isolation and characterization of the tsetse thrombin inhibitor: a potent antithrombotic peptide from the saliva of Glossina morsitans morsitans. Am J Trop Med Hyg 54: 475-480.

Champagne DE 2004. Antihemostatic strategies of blood-feeding arthropods. Curr Drug Targets 4: 375-396.

Champagne DE 2005. Antihemostatic molecules from saliva of Bloodfeeding arthropods. Pathophysiol Haemos Thromb 34: 221-227.

Champagne DE, Ribeiro JMC 1994. Sialokinin I and II: vasodilatory tachykinins from the yellow fever mosquito Aedes aegypti. Proc Natl Acad Sci USA 91: 138-142.

Cox JA 1938. Morphology of the digestive tract of the blackfly (Simulium nigroparvum). J Agr Res 57: 443-448.

Cross ML, Cupp MS, Cupp EW, Ramberg FB, Enriquez EJ 1993. Antibody responses of Balb/c mice to salivary antigens of hematophagous black flies (Diptera: Simuliidae). J Med Entomol 30: 725-734

Cupp EW, Cupp MS 1997. Black fly (Diptera: Simuliidae) salivary secretions: importance in vector competence and disease. $J$ Med Entomol 34: 87-94.

Cupp EW, Cupp MS, Ribeiro JMC, Kunz SE 1998. Blood-feeding strategy of Haematobia irritans (Diptera: Muscidae). J Med Entomol 35: 591-595.

Cupp MS, Cupp EW, Ochoa-a JO, Moulton JK 1995. Salivary apyrase in New World black flies and its relationship to Onchocerciasis vector status. Med Vet Entomol 9: 325-330. 
Cupp MS, Cupp EW, Ramberg FB 1993. Salivary gland apyrase in black flies. J Insect Physiol 39: 817-821.

Cupp MS, Ribeiro JMC, Cupp EW 1994. Vasodilative activity in black fly salivary glands. Am J Trop Med Hyg 50: 241-246.

Cupp MS, Zhang D, Cupp EW 2000. Horn fly saliva targets thrombin action in hemostasis (Diptera: Muscidae). J Med Entomol 37: 416-421.

Horn F, dos Santos PC, Termignoni C 2000. Boophilus microplus anticoagulant protein: an antithrombin inhibitor isolated from the cattle tick saliva. Arch Bioch Biophys 384: 68-73.

Hungerford HB 1913. Anatomy of Simulium vittatum. Sci Sci Bull 8: 365-382.

Jacobs JW, Cupp EW, Sardana M, Friedman P 1990. Isolation and caracterization of a coagulation factor Xa inhibitor from black fly salivary glands. Thromb Haemost 64: 235-238.

Jariyapan N, Takaoka H, Choochote W, Poovorawan Y, Otsuka Y, Jitpakdi A, Junkum A 2006. Morphology and electrophoretic protein profiles of female salivary glands in four oriental black fly species (Diptera: Simuliidae). J Vector Ecol 31: 406-411.

Laemmli UK 1970. Cleavage of the structural protein during assembly of the head of bacteriophage T4. Nature 227: 680-685.

Law JH, Ribeiro JMC, Wells MA 1992. Biochemical insights derived from diversity in insects. Rev Biochem 61: 87-112.

Lerner EA, Ribeiro JMC, Nelson RJ, Lerner MR 1991. Isolation of maxadilan, a potent vasodilatory peptide from the salivary glands of the sand fly Lutzomyia longipalpis. J Biol Chem 266: 11234-11236.

Lombardi C, Borges PC, Chaul A 1992. Environmental risk factors in endemic pemphigus foliaceus (fogo selvagem). J Invest Dermatol 98: 847-850.

Moreira-Ferro CK, Marinotti O, Bijovsky AT 1999. Morphological and biochemical analyses of the salivary glands of the malaria vector, Anopheles darlingi. Tissue Cell 31: 1-10.

Pinheiro FP, Bensabath G, Costa D, Maroja OM, Lins ZC, Andrade AH 1974. Hemorrhagic syndrome of Altamira. The Lancet 13: 639-642.
Py-Daniel V 1997. Oncocercose, uma endemia focal no hemisfério norte da Amazônia. In RI Barbosa, E Ferrera, EC Bermúdéz, Homem, ambiente e ecologia no estado de Roraima, INPA, Manaus, p. 111-155.

Ribeiro JMC 1987. Role of arthropod saliva in blood-feeding. Annu Rev Entomol 32: 463-478.

Ribeiro JMC 1995. Blood-feeding arthropods: live syringes or invertebrate pharmacologists? Infec Agents Dis 4: 143-152.

Ribeiro JMC, Francischetti IMB 2003. Role of arthropod saliva in blood feeding: sialome and post-sialome perspectives. Annu Rev Entomol 48: 73-88.

Rubtzov IA 1955. Variations in activity and blood sucking in connection with the gonotrophic cycle in Simuliidae. Trans Zool Inst Rus Acad Sci 21: 353-364.

Sauerbrey M 2008. The Onchocerciasis elimination program for the Americas (OEPA). Ann Trop Med Parasitol 102: 25-29.

Stark KR, James AA 1998. Isolation and characterization of the gene encoding factor Xa directed anticoagulant from the yellow fever mosquito, Aedes aegypti. J Biol Chem 273: 20802-20809.

Valenzuela JG, Belkaid Y, Rowton E, Ribeiro JMC 2001. The salivary apyrase of the bloodsucking sand fly Phlebotomus papatasi belongs to the novel Cimex family of apyrases. J Exp Biol 204: 229-237.

Valenzuela JG, Francischetti IMB, Ribeiro JMC 1999. Purification, cloning and synthesis of a novel salivary anti-thrombin from the mosquito Anopheles albimanus. Biochemistry 38: 11209-11215.

Valenzuela JG, Guimarães JA, Ribeiro JMC 1996. A novel inhibitor of factor X activation from the salivary glands of the bed bug Cimex lectularius. Exp Parasitol 83: 184-190.

Volf P, Tesarová P, Nohynkova E 2000. Salivary proteins and glycoproteins in phlebotomine sand flies of various species, sex and age. Med Vet Entomol 14: 251-256.

Zhang D, Cupp MS, Cupp EW 2002. Thrombostasin: purification, molecular cloning and expression of a novel anti-thrombin protein from horn fly saliva. Insect Biochem Mol Biol 32: 321-330. 